\title{
READINESS FOR INNOVATIVE ACTIVITY AS IMPORTANT PROFESSIONAL COMPETENCE OF NEW GENERATION ENGINEER
}

\author{
Aliya Murzagaliyeva, Bakytgul Jugembayeva \\ Al-Farabi Kazakh National University, Kazakhstan \\ altair.73@mail.ru, asbaku@mail.ru
}

\begin{abstract}
Qualitative training of an engineer with professional competence, capable to innovative activity, socially responsible, mobile, ready for continuous professional growth acquires special significance and relevance. The discrepancy between the level of skills and abilities formed by graduates and the level of real practical innovation environment leads to graduate unemployment, since university graduates are not in demand in innovation activities. Therefore, indispensable participation of students in scientific researches and development of real psychological and pedagogical problems become the main condition for the development of analytical, creative thinking. This, in its turn, contributes to the improvement of professional competence. As a result of this, human capital is formed, which is the main value of modern higher education.
\end{abstract}

Keywords: innovation, competence, motivation, innovation, engineering education.

\section{Introduction}

Currently, in the context of large-scale reforms aimed at creating a favorable economic and social environment in the Republic of Kazakhstan (the RK), the transition to the innovative development of the economics is becoming one of the priority directions of the country's socio-economic development. To achieve this goal the Innovative Development Concept of the Republic of Kazakhstan until 2020 (further "the Concept") was developed (approved by the Decree of the President of the Republic of Kazakhstan No. 579, dated June 4, 2013), where the key role is given to innovation. At the same time, in modern society the role of engineering activity is constantly increasing, and the problem of training highly qualified new generation engineers acquires special significance and relevance.

One of the urgent problems indicated in the Concept is the "unpreparedness of the national education system to the challenges of accelerated industrialization and the fulfillment of tasks for the development of high-tech sectors of the economics" [1]. Analysis of the current state of higher and postgraduate education shows that the education system is going through a period of rethinking approaches, rejecting a number of established traditions and stereotypes. It should be noted that today Kazakhstan is faced with a new problem, which is interpreted as "graduated unemployment". This is unemployment among university graduates with a professional diploma, which, however, remain unclaimed in innovation.

In order to improve the quality of education and solve the problem of inconsistency of the quality of education with the needs of the innovation economics, training of specialists is based on the competence approach. This, in its turn, drastically affects the factors that underlie in the foundation of effective implementation of innovation and are associated with the characteristics of its subject.

\section{Research methodology}

Basic methods of scientific research will be used in the study, i.e. systemic, activity and process approaches to the investigation of the system of faculty member motivation to innovation activity as a complex and multi-aspect phenomenon of the present economic situation.

In pedagogy it is accepted to distinguish between the concepts of "competence" and "competency."

Competency is a predetermined requirement for the educational preparation of a student, a characteristic of his professional role.

Professional competence is a measure of compliance with this requirement, the degree of development of competence, unity in the integral personality structure of theoretical and practical readiness [2]. Note that the professional competence of a teacher is understood as a system of knowledge, skills and abilities that form the basis of his professional activity as a teacher and scientist.

Thus, a university teacher as an object and subject of education must have not only knowledge in the professional sphere, skills and abilities of the profession he has acquired, but also have the ability 
to navigate in a difficult modern situation, to predict and make decisions. In this regard, the readiness of teachers to innovation activity becomes a key task.

The theoretical readiness of a university teacher in the structure of his professional competence is manifested in constructive and gnostic activity. The main competencies are analytical, projective and reflexive.

The practical readiness of a university teacher in the structure of his professional competence is expressed in the subject competencies, which are represented by organizational and communication skills [2].

Thus, teachers' readiness to implement innovations requires an innovative approach to ensuring the quality of student learning, a new approach to the organization of the educational process, and it also influences the development of the professional competence. Therefore, the level of professional competence of the teacher becomes one of the main factors affecting the quality of education.

Today in economically developed countries in the system of higher and postgraduate education four models of universities are considered:

- "University 1.0" - 1 mission (education);

- "University 2.0" - 2 missions (education, science);

- "University 3.0" - 3 missions (education, science, commercialization);

- "University 4.0" - 4 missions (education, science, commercialization, creativity).

The ability to generate new scientific knowledge on the basis of a wide range of basic and applied research, the possibility of technology transfer to the real economics, the availability of an effective system of training highly qualified personnel determines the innovative way for leading higher educational institutions.

The analysis of the current trends in the innovative development of the economics of the leading Western countries shows that in the era of the fourth industrial revolution the transformation of the enterprise's (organization's) knowledge into intellectual resources and then into intellectual capital becomes the main factor of the innovation economic model. Note that the concept of intellectual capital has been developed as a resource for increasing the profitability and value of enterprises (organizations). Today there are various models and theories of intellectual capital, but almost all researchers of this issue distinguish three components of intellectual capital: human, organizational, client [3]. The analysis shows that the interrelation and harmonious interaction of these capitals leads to the social development of the enterprise (organization), which in turn affects the social development of society. Therefore, human capital, by which we mean the stock of knowledge, skills, abilities and motivations, occupies the main position.

If you interview employees of an enterprise (organization) of various positions, which factor is most important in achieving success, then most of them will answer that this is leadership. Note that leadership plays a key role in politics, business, education and many other spheres of activity. Thus, the formation and development of human capital in the conditions of the country's transition to an innovative economics are of particular relevance, and readiness becomes a key component of effective functioning and development of human capital.

The Al-Farabi Kazakh National University (Al-Farabi Kazakh National University) is the leading university in Kazakhstan, a leader in the ranking of the Independent Kazakhstan Agency for Quality Assurance in Education (IKAQAE), winner of the President of the Republic of Kazakhstan award "For achievements in the field of quality". Note that the United Nations (UN) has entrusted to head the Global Hub of the UN Program "Academic Impact" KazNU in the name of Al-Farabi, as a leader in education and science.

According to the definition, leadership is a process by which one individual influences the behavior of others and organizes their activities in accordance with the tasks set before the organization [4]. Firstly, leadership is a process that should stimulate innovative behavior of university staff.

The Al-Farabi Kazakh National University has developed and approved the University's Development Strategy for 2015-2020 (hereinafter referred to as the Strategy). The purpose of the Strategy is to transform the national classical university into a research university, the concept of 
which is based on the effective interaction of the scientific, technical, educational and industrial complexes, which are aimed at introducing at the enterprises scientific and innovative developments created in the departments of higher educational institutions and in the laboratories of scientificresearch institutes (SRI). Consequently, the ability of KazNU named after Al-Farabi to develop and implement effective innovations of a technological, organizational and commercial nature ensures the innovative behavior of the university teachers and SRI employees.

Secondly, in the definition of the term "affects" means that the leader acts as a catalyst for joint activities, searches for a goal and, thanks to a common strategy, unites partners to solve emerging problems.

Analysis of the conducted research shows that resource and organizational support for scientific and innovation activity will improve the integration of education and science, support for partnership relations between business, government agencies and higher education institutions. Investment by the state and the private sector in intangible assets, in providing conditions for the continuous realization of knowledge in high-tech products and services, is associated with the increasing role of the human factor in the innovative development of the country's economics. Consequently, a university teacher and scientific employee become partners in a common corporate business, which product is knowledge. That knowledge should be the object of accounting, monitoring, periodic updates.

The need for an innovative focus in pedagogical and scientific activities acts as a means of updating the educational policy. Changes in the volume of academic disciplines, analysis of new research results to highlight what is directly related to the business, require a constant search for various organizational forms and technologies. Thus, the nature of innovation processes is determined by the content of the results obtained, the degree of complexity and novelty of the proposals being implemented, as well as readiness for innovation activities.

A clear idea of the content and criteria of pedagogical innovations, knowledge of the method of their application allows both individual teachers and heads of higher educational institutions to objectively evaluate and predict their implementation. Search for the necessary information, assessment of its reliability and relevance are the beginning of the commercialization of new promising results:

1. for the development of science the main indicator is the number of published articles;

2. to determine the quality of scientific research - the number of citations of journals in which articles are published;

3. for use of scientific information - the number of open full-text articles.

\section{Conclusions}

In real life, the integrative form of universities and research organizations does not meet the needs of the innovative development of the economics and the gap between the theoretical knowledge that students acquire in universities and the practical skills that most employers expect from them is becoming increasingly noticeable. Therefore, graduates of universities of an enterprise (organization) are considered not as ready-made specialists, but as their personnel potential.

This problem is explained by the low rate of introduction and use by state organizations and higher educational institutions of modern technologies, weak innovative orientation, which does not meet either the needs of its development or the world standards. It should be noted that the result of innovation processes in education should be the use of innovations, both theoretical and practical, as well as those formed at the intersection of theory and practice.

"Improving the efficiency of science and education" [1] is one of the strategic objectives of the Concept. The forced and large-scale development of new technologies leads to the fact that the organization and content of the educational process do not have time to undergo adequate changes. New requirements dictate the need for radical modernization of the system of Kazakhstan higher education.

Today, the mechanism of establishing the interaction between science, education and business is the dual education system, which is used in such areas as economics, technology and social welfare. To do this, it is necessary to intensify the relationship of science with business, to use new knowledge, achievements of science and technology in educational activities, to attract students to conduct 
research. This, in turn, will help eliminate barriers that have developed between universities and research institutes with individual employers and the labor market as a whole. It will also allow to qualitatively prepare an engineer with professional competence, capable of innovation, socially responsible, mobile, and ready for continuous professional growth.

Under readiness is understood the set of internal motives to ensure the success of the development and implementation of activities. Indicators of the readiness of engineers to implement innovations:

1. expression of interest in innovation and its dynamics;

2. desire to evaluate their professional and personal experience from the standpoint of innovation;

3. positive attitude towards the prospects for innovation;

4. awareness of their capabilities, the need to work on themselves;

5. engineer's awareness of the insufficiency of the achieved results and the desire to improve them.

Thus, the continuous development of new technologies, the degree of complexity and novelty of the proposals being implemented determine the nature of the training of engineers, who will be able to accomplish the tasks of accelerated industrial and innovative development.

To achieve this goal, legislative support for scientific and innovation activities is constantly being improved, government support for scientific and innovation development is increasing through a competitive system of financing scientific projects. Thus, the state receives guarantees that the obtained research and development will be economically efficient, joint activities of higher educational institutions, scientific foundations and organizations with business associations will ensure innovative growth of the national economics. This means that the generation and spreading of knowledge are becoming important factors in creating the long-term, sustainable competitive advantages of national economics.

The Rector of the Al-Farabi Kazakh National University at a special conference of the USRN, which was held at the University of Saint-Paulo, presented a new model "University 4.0". It includes 4 missions (education, science, commercialization, creativity). The model proposed by the Rector is aimed at finding new ways of development, namely, it is a mechanism for bridging the gap and forging interaction between science, education and business. Thus, the training of competent and competitive specialists, who are ready to create and implement innovative projects in all areas of the country's socio-economic development, is an integrative indicator of economic development.

Under current conditions the ability to perceive and generate knowledge, the development and use of intellectual resources increase the importance of a creative attitude to work and high professionalism. Therefore, consideration of the personality of an engineer from the "human capital" position means the study of such individual and personal qualities of a subject that an engineer must possess in order to realize his creative potential in the context of innovative activity. Namely, the need for self-development, the desire for self-improvement and self-realization.

The experience of the developed countries of the world shows that the key to the tripartite interaction is a successfully functioning and effectively managed education system. Universities are the link between fundamental applied science and business. The implementation of a new educational content requires the introduction of new technologies. The main condition for the development of analytical, creative thinking, as well as the elimination of "graduated unemployment" is the indispensable participation of students in scientific research and the development of real psychological and pedagogical problems. As a result of this, human capital is formed, which is the main value of modern higher education.

\section{References}

[1] The concept of innovative development of the Republic of Kazakhstan until 2020. [online][16.02.2019] Available at: http://online.zakon.kz/Document/doc_id = 31409916 .

[2] Slastenin V.A. Pedagogy. - M., 2015, 491 p.

[3] Zinov V.G., Lebedeva T.Ya., Tsyganov S.A. Innovative development of the company. - M., 2009, $245 \mathrm{p}$.

[4] Volkogonova O.D., Zub A.T. Management psychology. - M., 2005, 350 p.

[5] The Fourth Industrial Revolution: Internet of Things, Circular Economics and Blockchain [online][16.02.2019] Available at: http://www.furfur.me/furfur/changes/changes/216447-4-ayapromyshlennaya-revolyutsiya. 